\title{
CARBOXYPEPTIDASE Y CATALYZED \\ C-TERMINAL MODIFICATION IN THE B-CHAIN OF PORCINE INSULIN
}

\author{
by \\ KLAUS BREDDAM, FRED WIDMER and JACK T. JOHANSEN
}

Department of Chemistry, Carlsberg Laboratory, Gamle Carlsberg Vej 10, DK-2500 Copenhagen Valby

Keywords: Enzymatic synthesis, protein semisynthesis, carboxypeptidase Y, insulin

It is demonstrated that carboxypeptidase $\mathrm{Y}$ can be used to exchange the $\mathrm{C}$-terminal alanyl residue of porcine insulin with a threonyl residue, thus forming human insulin. Using threonine amide as nucleophile, the reaction proceeds as a transpeptidation via human insulin amide, des(Ala)B30(Thr- $\left.\mathrm{NH}_{2}\right)^{\mathrm{B} 30}$ insulin. However, since the amidase activity of carboxypeptidase $\mathrm{Y}$ towards this particular insulin derivative is significant in comparison with its peptidase activity towards porcine insulin, various secondary products are subsequently formed. One of these products is human insulin, formed by deamidation of the initial coupling product. Unfortunately, this product cannot be separated chromatographically from the hydrolysis product des(Ala)B30insulin and residual

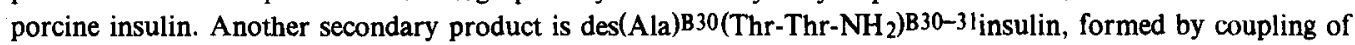
an additional threonine amide residue via the amidase activity of carboxypeptidase $Y$. This product, together with the primary coupling product, $\operatorname{des}(\mathrm{Ala}) \mathrm{B} 30\left(\mathrm{Thr}-\mathrm{NH}_{2}\right) \mathrm{B} 30$ insulin, can be isolated from the reaction mixture by ion exchange chromatography, and both of these insulin derivatives can subsequently be converted to human insulin through the peptidyl amino acid amide hydrolase activity and amidase activity of carboxypeptidase $\mathrm{Y}$. The semisynthetic human insulin formed in this fashion is essentially pure.

It is further demonstrated that carboxypeptidase $\mathrm{Y}$ can be used to replace the $\mathrm{C}$-terminal residue in another insulin derivative without significant side-reactions. Des(Ala)B30insulin is a much better substrate of CPD-Y than porcine insulin, resulting in a coupling product exhibiting a much higher stability towards degradation. Thus, the conversion of des(Ala)B30insulin to des(Lys-Ala)B29-30(Thr-OH)B29insulin is completely free of side reactions.

Abbreviations: CPD-A = carboxypeptidase A; CPD-Y = carboxypeptidase $\mathrm{Y}$; Dns = dansyl; $\mathrm{DPCC}=$ diphenyl carbamyl chloride; HPLC = high pressure liquid chromatography. Since only the C-terminal of the Bchain of insulin is involved in these reactions, INS-Pro-Lys-Ala-OH is used as an abbreviation of porcine insulin. Other insulin derivatives are thus abbreviated accordingly: INS-Pro-Lys-OH $=\operatorname{des}(\mathrm{Ala}) \mathrm{B} 30 \mathrm{insulin}$, INS-Pro-OH $=$ des(Lys-Ala)B29-30insulin, etc. 


\section{INTRODUCTION}

In previous papers $(1,3)$, we have demonstrated that carboxypeptidase $\mathrm{Y}$ (CPD-Y)' can catalyze the exchange of $\mathrm{C}$-terminal amino acids in short peptides by transpeptidation reactions. The results indicated that CPD-Y might become a tool for C-terminal semisynthesis of longer peptides and proteins. In order to explore this capacity of CPD-Y, we have chosen porcine insulin as an example. Since the C-terminal segment of the B-chain of insulin is known to be important for its biological activity, this region of the molecule has already been the subject of various semisynthetic manipulations $(5,7)$. The potential of being able to convert porcine insulin to human insulin, which only differ by the presence of a threonyl residue in human insulin and an alanyl residue in porcine insulin in the $\mathrm{C}$ terminal position of the B-chain, and thus obtaining sufficient material for clinical evalua. tion of human insulin, has resulted in great interest for such reactions. Among the published procedures for semisynthesis of human insulin, some involve tryptic cleavage of porcine insulin to form des(octapeptide) ${ }^{\mathrm{B} 23-30}$ insulin to which is coupled a synthetic octapeptide with the Cterminal sequence of human insulin $(9,14,15)$. Other and more recent procedures involve a carboxypeptidase A catalyzed formation of $\operatorname{des}(\mathrm{Ala})^{\mathrm{B} 30}$ insulin (18) to which a threonine derivative is enzymatically coupled $(6,9,12)$. In the present paper we demonstrate that CPD-Y can be used to convert porcine insulin to human insulin via des(Ala) ${ }^{\mathrm{B} 30}\left(\mathrm{Thr}-\mathrm{NH}_{2}\right)^{\mathrm{B} 30}$ insulin (human insulin amide). Similar reactions are shown to be possible using des(Ala $)^{\mathrm{B} 30}$ insulin as substrate.

\section{MATERIALS AND METHODS}

\subsection{Materials}

Carboxypeptidase Y from baker's yeast, a commercial preparation from the Carlsberg Breweries, was isolated by a modification of the affinity chromatographic procedure of JOHANSEN et al. (10) and obtained as a lyophilized powder $(10 \%$ enzyme in sodium citrate). Before use the enzyme was desalted on a Sephadex G-25 column $(1.5 \times 25 \mathrm{~cm})$ equilibrated and eluted with water. The concentration of the enzyme was determined spectrophotometrically using
$E_{280 \mathrm{~nm}}^{1 \%}=14.8$. The enzyme preparation used was free of Protease A as checked by the assay of LEE and RIORDAN (11).

Porcine insulin and an authentic sample of human insulin was a generous gift from Nordisk Insulinlaboratorium, Denmark, through the courtesy of Dr. B. HANSEN. L-threonine amide was purchased from Vega-Fox, USA. L-threonine methyl ester was from Fluka, Switzerland, and L-threonine, dansyl chloride, carboxypeptidase A and trypsin were obtained from Sigma, USA. Chromatographic materials were products of Pharmacia, Sweden. All other reagents and solvents were analytical grade from Merck, W. Germany.

\subsection{Methods}

Enzymatic reactions were performed in a $\mathrm{pH}$ stat in $0.1 \mathrm{~m}-\mathrm{KCl}, 2 \mathrm{~mm}$-EDTA, and the $\mathrm{pH}$ was kept constant by addition of $0.5 \mathrm{M}-\mathrm{NaOH}$. Due to a low solubility of insulin at $\mathrm{pH} 7.5,1.5 \mathrm{M}$ guanidine hydrochloride was added to the reaction mixture. $\mathrm{Zn}$-free insulin, prepared as described by SluYterman (19) was used throughout. Reactions were quenched by adjusting the $\mathrm{pH}$ to $1.5-2.0$ with $1 \mathrm{M}-\mathrm{HCl}$. If precipitation appeared, $1 \mathrm{~m}$-acetic acid was added until all material was dissolved. The insulin fraction was separated from the enzyme and low molecular weight compounds by chromatography on a Sephadex G-50 fine column, equilibrated with 1 M-acetic acid (17), and lyophilized.

Chromatography on DEAE Sephadex A-25 was performed essentially as described by MORIHARA et al. (13). The lyophilized insulin sample was dissolved in $0.01 \mathrm{M}$-Tris, $2.5 \mathrm{M}$-urea, 0.05 $\mathrm{m}-\mathrm{NaCl}, \mathrm{pH} 7.5$ and applied to a DEAE Sephadex A-25 column equilibrated with the same buffer. The insulin was eluted with a $\mathrm{NaCl}$ gradient from 0.05 to $0.30 \mathrm{M}$ in the same buffer. The pooled fractions were desalted on a Sephadex G-25 column and lyophilized. Disc gel electrophoresis was performed according to Davis (4) using a $12.5 \%$ polyacrylamide gel.

Digestion of various insulin derivatives with carboxypeptidases $\mathrm{A}$ and $\mathrm{Y}$ were performed in a $0.05 \mathrm{~m}$-Tris buffer, $\mathrm{pH} 7.5$ at room temperature using approximately $1.5 \mathrm{~mm}$-insulin and $5 \mu \mathrm{M}$ carboxypeptidase. Reaction times were 3 hours 
with CPD-A and 1.5 hours with CPD-Y. Under these conditions maximal release of $\mathrm{C}$-terminal amino acids were obtained. After acidification with $\mathrm{HCl}$, the aliquots were applied directly on the amino acid analyzer.

The sequence of the C-terminal amino acid residues of the various insulin derivatives were determined after reaction of a trypsin digest with dansyl chloride, followed by identification of the dansyl peptides. Digestion of insulin derivatives with trypsin was performed in $0.1 \mathrm{M}-\mathrm{NaHCO}_{3}$ at $\mathrm{pH} 8.2$, using $1 \mathrm{~mm}$-insulin, $40 \mu \mathrm{M}$-DPCCtrypsin and an incubation time of 1 hour. Preliminary experiments on porcine insulin had indicated that these conditions were sufficient for complete release of the $\mathrm{C}$-terminal alanyl residue from the B-chain. The released amino acids or dipeptides were dansylated as follows: A $100 \mu \mathrm{l}$ sample of the tryptic digestion mixture was quenched by addition of $100 \mu \mathrm{l} 0.5 \mathrm{M}-\mathrm{HCl}$. The aliquot was evaporated to dryness and redissolved in $100 \mu \mathrm{l} 0.1 \mathrm{M}-\mathrm{NaHCO}_{3}, \mathrm{pH} 8.2 .100 \mu \mathrm{l}$ dansyl chloride $\left(5 \mathrm{mg} \cdot \mathrm{ml}^{-1}\right)$ in acetone was added, and the reaction mixture incubated for 2 hours at $37^{\circ} \mathrm{C}$. The reaction mixture was then analyzed by HPLC, using the Waters liquid chromatography system, consisting of a Model U6K injektor, two Model 6000 A pumps, a Model 660 Solvent Programmer, a Model 450 UV detector, a Waters Data Module and a Waters Radial Compression Module (RCM 100) housing equipped with a Waters Radial Pak A (C-18 reverse phase) column. The following standard compounds were synthesized: Dns-Ala$\mathrm{OH}$, Dns-Ala-Thr-OH, Dns-Thr-Thr-OH, DnsThr-NH ${ }_{2}$, Dns-Thr-Thr-NH 2 and Dns-Ala-Thr$\mathrm{NH}_{2}$. Using the procedure described above for the dansylation of insulin digestions, three of these derivatives could be synthesized from $\mathrm{H}$ Ala-OH, H-Thr-OH and H-Thr-NH 2 . The dansylated dipeptides were synthesized via Dns-Ala$\mathrm{OMe}$ and Dns-Thr-OMe: $1 \mathrm{mmol} \mathrm{H}$-Ala$\mathrm{OMe} \cdot \mathrm{HCl}$ was dissolved in $0.1 \mathrm{M}-\mathrm{NaHCO}_{3} ; 5$ mmol of dansyl chloride was added, and the reaction mixture incubated for 2 hours. The Dns-Ala-OMe was extracted from the reaction mixture with ethyl acetate and evaporated to dryness. It was demonstrated by HPLC that the isolated material was pure. The same procedure was used to synthesize Dns-Thr-OMe. Using procedures for enzymatic peptide synthesis simi-

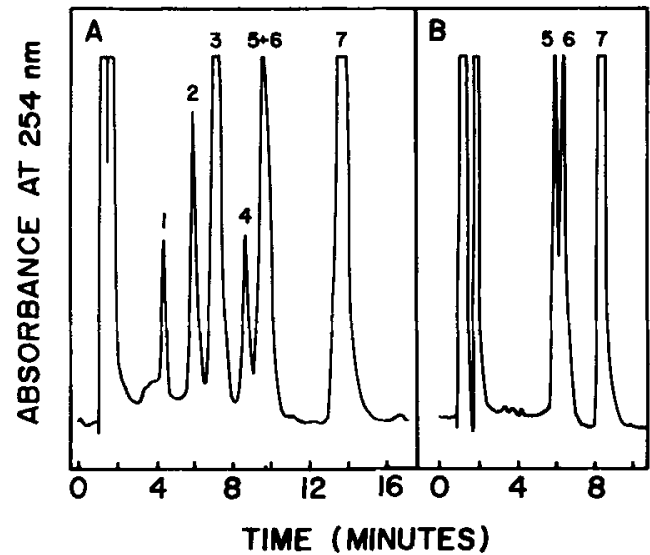

Figure 1. HPLC chromatograms of dansyl standard compounds using a Waters Radial Pak A (C-18 reverse phase) column and the following eluant system. A-buffer: $10 \mathrm{~mm}$-sodium acetate, $\mathrm{pH} \mathrm{4.0,} \mathrm{B-}$ buffer: $80 \%$ acetronitrile $+20 \%$ A.

The separation was carried out at room temperature and monitored at $254 \mathrm{~nm}$. The flow-rate was 1 $\mathrm{ml} \cdot \mathrm{min}^{-1}$. Two different elution programs were used: Panel A: $35 \%$ B isocratic. Panel B: $40 \%$ B to $70 \%$ B in 30 minutes using a linear gradient. By cochromatography of authentic samples the following peak assignments were made: $1=$ Dns-Thr-Thr-OH, $2=$ Dns-Ala-Thr-OH, $3=$ Dns-Thr-OH, $4=$ DnsThr-Thr-NH $2,5=$ Dns-Ala-Thr-NH $\mathrm{NH}_{2}, 6=$ DnsThr- $\mathrm{NH}_{2}, 7=$ Dns-Ala-OH.

lar to those previously described $(1,2,20,21$, 22,23 ), these two compounds were then coupled to $\mathrm{H}-\mathrm{Thr}-\mathrm{OH}$, giving Dns-Ala-Thr-OH and DnsThr-Thr-OH, and H-Thr- $\mathrm{NH}_{2}$, giving Dns-Ala$\mathrm{Thr}-\mathrm{NH}_{2}$ and Dns-Thr-Thr-NH . The conditions were as follows: $5 \mathrm{~mm}$ substrate, $0.5 \mathrm{M}$ nucleophile, $0.1 \mathrm{M}-\mathrm{KCl}, 2 \mathrm{~mm}-\mathrm{EDTA}, 1 \mu \mathrm{M}-$ CPD-Y, pH 9.0, 10\% ethanol. As shown in Figure 1 all seven dansyl derivatives could readily be separated by HPLC using two different programs.

Amino acid compositions were determined after hydrolysis for 24 hours in $6 \mathrm{M}-\mathrm{HCl}$. The amino acid compositions were based on the known content in insulin of 4 glycine and 3 aspartic acid. Only the content of Thr, Lys and Ala is listed in the transpeptidation reactions, since these are the only amino acids affected by the reactions. The amino acid analysis of these amino acids for porcine insulin are: $\mathrm{Thr}=1.93$, Lys $=0.97$ and $\mathrm{Ala}=2.00$ and for authentic 
human insulin: Thr $=2.87$, Lys $=0.98$ and $\mathrm{Ala}=1.05$. The amount of unconverted porcine insulin in the reaction mixture was estimated from the alanine content of the insulin pool after chromatography on Sephadex G-50. The coupling yield is defined as the amount of a given product divided with the amount of all insulin consumed in the reaction. Deamidation of the various insulin amide fraction were performed at pH 10.0 in $0.1 \mathrm{M}-\mathrm{KCl}, 2 \mathrm{~mm}$-EDTA, using 10 $\mu \mathrm{M}$-CPD-Y for $20 \mathrm{~min}$. The extent of the deamidation was followed by disc gel electrophoresis and optimized with respect to time of incubation and concentration of CPD-Y. The deamidated product was chromatographed on DEAE Sephadex A-25 using conditions as described above.

\section{RESULTS}

\subsection{Conversion of porcine insulin to human insulin}

To investigate the feasibility of an enzymatic conversion of porcine insulin to human insulin it was investigated whether the C-terminal alanyl residue in the B-chain could be split off without releasing the $\mathrm{C}$-terminal asparagine in the $\mathrm{A}$ chain. Digestion of porcine insulin with CPD-Y released only the six amino acids from the $C$ terminal portion of the B-chain, -Phe-Tyr-ThrPro-Lys-Ala-OH (Table I). Importantly, the LeuThr ${ }^{\mathrm{B}}{ }^{5-16}$ bond was not hydrolyzed confirming that the CPD-Y preparations used in these

\section{Table I}

Amino acids released by CPD-Y digestion of porcine insulin.

\begin{tabular}{cc}
\hline Amino acid & Residues/mole \\
\hline Ala & 1.01 \\
Lys & 1.00 \\
Pro & 1.08 \\
Thr & 1.00 \\
Tyr & 1.01 \\
Phe & 1.13 \\
Asn & 0.00 \\
Leu & 0.00 \\
\hline
\end{tabular}

Reaction conditions: $1 \mathrm{~mm}$-porcine insulin, $0.05 \mathrm{M}$ Tris, I mM-EDTA, pH 7.5, $2 \mu \mathrm{M}$ CPD-Y, time of incubation: 2 hours.

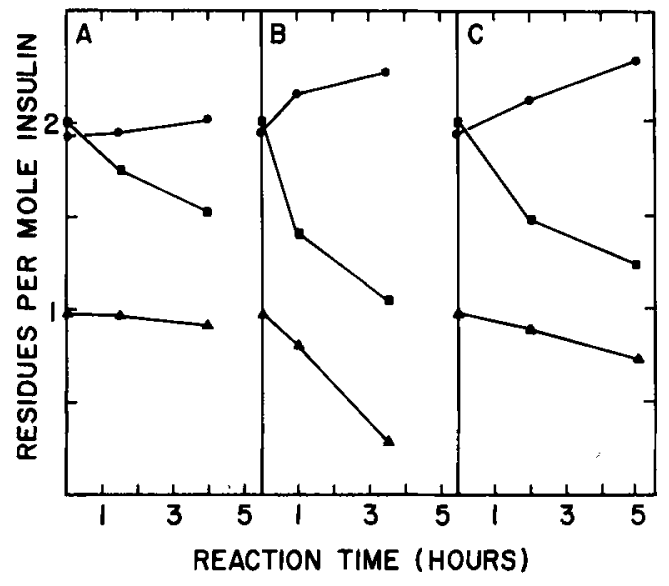

Figure 2. Time course for the CPD.Y catalyzed transacylation reactions on porcine insulin.

Conditions were as follows: (A) $4 \mathrm{~mm}$-insulin, 0.7 м H-Thr-OH, $25 \mu$ M CPD-Y, pH 9.5. (B) 0.5 mminsulin, 0.5 м H-Thr-OMe, $15 \mu \mathrm{M}$ CPD-Y, $\mathrm{pH} 9.5$. (C) 2 mM-insulin, 0.2 м H-Thr-NH $2,24 \mu \mathrm{M}$ CPD-Y, pH 9.5. Amino acid content of the synthesized insulin: - Thr, Ala, $\Delta$ Lys. Reactions were quenched and analyzed as described in section 2 .

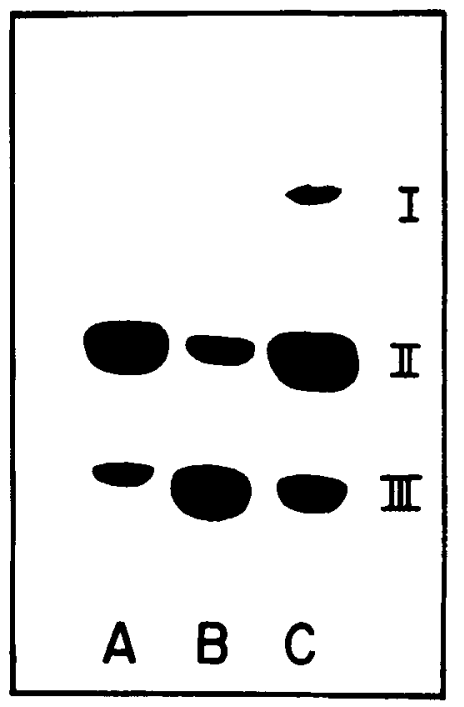

Figure 3. Disc gel electrophoresis of the insulin derivatives formed in the reactions described in Figure 1.

(A) corresponds to Figure $1 \mathrm{~A}$, (B) corresponds to Figure $1 \mathrm{~B}$, and $(\mathrm{C})$ corresponds to Figure $1 \mathrm{C}$. The bands indicated by I, II and III are comprised of the following insulin species: (I): INS-Pro-Lys-Thr- $\mathrm{NH}_{2}$, INS-Pro-Lys-Thr-Thr-NH 2 . (II) INS-Pro-Lys-Ala$\mathrm{OH}$ (porcine insulin), INS-Pro-Lys-Thr-OH (human insulin), INS-Pro-Lys-OH, INS-Pro-Thr- $\mathrm{NH}_{2}$. (III) INS-Pro-OH and other des(Ala-Lys)B29-30insulin derivatives. 


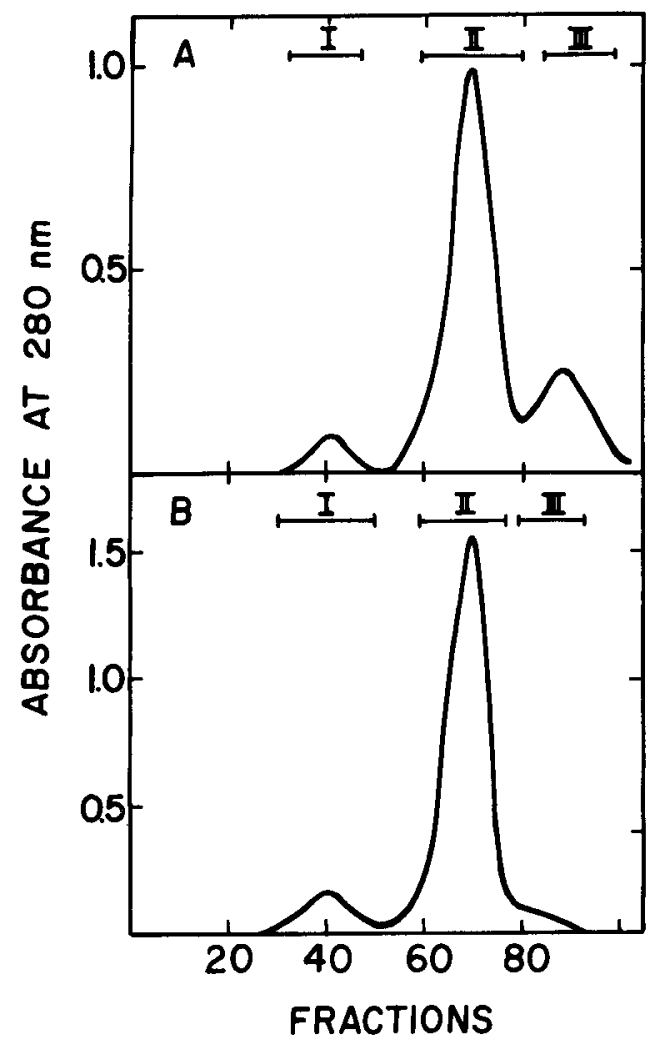

Figure 4. DEAE chromatography of the combined insulin derivatives formed in the CPD-Y catalyzed reaction between porcine insulin and $\mathrm{H}-\mathrm{Thr}-\mathrm{NH}_{2}$ at pH 9.5 .

A: The reaction conditions were: $2 \mathrm{~mm}$-porcine insulin, $0.25 \mathrm{~m} \mathrm{H}-\mathrm{Thr}-\mathrm{NH}_{2}, 30 \mu \mathrm{M}-\mathrm{CPD}-\mathrm{Y}, \mathrm{pH}$ 9.5, reaction time 4 hours. The amino acid composition of the insulin pool after chromatography on Sephadex G. 50 (Table II A) indicated that $76 \%$ of the porcine insulin had been consumed in the reaction. $60 \mathrm{mg}$ reacted insulin was applied to the DEAE column (2.6 $\times 20 \mathrm{~cm}$ ). Volume of collected fractions: $3.5 \mathrm{ml}$.

B: The reaction conditions were: 2 mm-porcine insulin, $0.25 \mathrm{M} \mathrm{H}-\mathrm{Thr}-\mathrm{NH}_{2}, 15 \mu \mathrm{M}-\mathrm{CPD}-\mathrm{Y}, \mathrm{pH}$ 9.5, reaction time 1 hour. The amino acid composition of the insulin pool after chromatography on Sephadex G-50 (Table II B) indicated that $31 \%$ of the porcine insulin had been consumed in the reaction. $215 \mathrm{mg}$ reacted insulin was applied to the DEAE column (2.6 $\times 50 \mathrm{~cm}$ ). Volume of collected fractions: $10 \mathrm{ml}$.
Table II A

Amino acid compositions of the peaks in Figure $4 \mathrm{~A}$.

\begin{tabular}{lcccc}
\hline & Pool & Peak I & Peak II & Peak III \\
\hline Thr & 2.56 & 3.88 & 2.27 & 2.76 \\
Ala & 1.24 & 1.13 & 1.30 & 1.25 \\
Lys & 0.68 & 0.94 & 0.92 & 0.05 \\
Area (\%) & & 3 & 77 & 20 \\
\hline
\end{tabular}

Insulin components:

Peak I: $\quad 100 \%$ INS-Pro-Lys-Thr-Thr-NH $\mathrm{NH}_{2}$

Peak II: $\quad 40 \%$ INS-Pro-Lys-OH

$22 \%$ INS-Pro-Lys-Thr-OH

$30 \%$ INS-Pro-Lys-Ala-OH

$8 \%$ INS-Pro-Thr- $\mathrm{NH}_{2}$

Peak III: Degradation products

Table II B

Amino acid compositions of the peaks in Figure 4 B.

\begin{tabular}{lcccc}
\hline & Pool & Peak I & Peak II & Peak III \\
\hline Thr & 2.17 & 4.01 & 2.01 & 2.29 \\
Ala & 1.69 & 1.03 & 1.81 & 1.64 \\
Lys & 0.93 & 1.00 & 0.95 & 0.67 \\
Area (\%) & & 7 & 91 & 2 \\
\hline
\end{tabular}

Insulin components:

Peak I: $\quad 100 \%$ INS-Pro-Lys-Thr-Thr-NH 2

Peak II: $\quad 81 \%$ INS-Pro-Lys-Ala-OH

$13 \%$ INS-Pro-Lys-OH

$3 \%$ INS-Pro-Thr- $\mathrm{NH}_{2}$

$3 \%$ INS-Pro-Lys-Thr-OH

Peak III: Degradation products

The amino acid composition of the pool refers to the analysis of the insulin fraction after its separation from enzyme and low molecular weight materials by gel chromatography on Sephadex G-50. The peak composition is based on the amino acid composition of individual peaks and the results of the digestion experiments with CPD-Y and CPD-A (see section 2). studies were free of Protease A. This is in contrast to many preparations commercially available from other sources (11).

When insulin was incubated with CPD-Y at $\mathrm{pH} 9.5$ in the presence of the nucleophiles $\mathrm{H}$ -
Thr-OH, H-Thr-OMe or H-Thr-NH ${ }_{2}$, the results presented in Figure 2 were obtained. With $\mathrm{H}$ Thr- $\mathrm{OH}$ as nucleophile (Figure $2 \mathrm{~A}$ ), no transpeptidation was observed. However, with $\mathrm{H}$ Thr-OMe and $\mathrm{H}-\mathrm{Thr}-\mathrm{NH}_{2}$ (Figure $2 \mathrm{~B}$ \& $\mathrm{C}$ ) 
transpeptidation did occur as indicated by the decreasing alanine content and the increasing threonine content of the insulin pool (obtained after chromatography on Sephadex G-50). Disc gel electrophoresis of aliquots from the experiments shown in Figure 2, was used to estimate the amount of reaction products with a blocked C-terminal carboxylic acid group, since such insulin derivatives exhibit a slower mobility than porcine and human insulin. In Figure 3 it is shown that with $\mathrm{H}-\mathrm{Thr}-\mathrm{NH}_{2}$ as nucleophile only a small proportion of insulin derivative with blocked C-terminal carboxylic acid group was formed (Band 1). When H-Thr-OMe was used no such derivative was formed.

In order to further analyze the reactants present in each of the three bands observed in disc gel electrophoresis, ion exchange chromatography on DEAE Sephadex A-25 was used to obtain sufficient material of these species. As expected, a total of three peaks were observed in the elution profile (Figure 4), and disc gel electrophoresis of each peak indicated that they corresponded to the bands in the disc gel of the mixture. Using ion exchange chromatography, it could be confirmed that the reaction mixture of a transpeptidation performed at $\mathrm{pH} 9.5$ with $\mathrm{H}$ $\mathrm{Thr}-\mathrm{NH}_{2}$ as nucleophile, contained very little (3\%) of the insulin derivatives migrating as Band I in disc gel electrophoresis and as Peak I in the ion exchange chromatography (Figure $4 \mathrm{~A}$ ). The amino acid compositions of the individual peaks and the results of carboxypeptidase digestion experiments performed with CPD-Y and CPD-A were used to determine the composition of the peaks (Table II A). It is apparent from the data in Figure $4 \mathrm{~A}$ and Table II $\mathrm{A}$ that most of the threonine incorporated at $\mathrm{pH} 9.5$ exists in Peak II as human insulin, INS-Pro-Lys-Thr-OH, suggesting that the release of ammonia from the primary coupling product, INS-Pro-Lys$\mathrm{Thr}-\mathrm{NH}_{2}$, is faster under these conditions than the release of alanine from porcine insulin, INSPro-Lys-Ala-OH. This is further demonstrated by the fact that Peak I has a threonine content of 3.88 , indicating that it is composed of INS-ProLys-Thr-Thr- $\mathrm{NH}_{2}$ rather than the initial coupling product. These conditions are therefore only suitable for a one-step synthesis of human insulin, but since this product elutes in Peak II together with unconverted porcine insulin and the hydrolysis product, INS-Pro-Lys-OH, the method has only limited applicability. The trypsin digestion followed by dansylation demonstrated that Peak II is free of insulin species such as INS-Pro-Lys-Thr-Thr-OH. The total yield of the conversion of porcine insulin to human insulin can therefore be estimated to be $30 \%$ when unconverted porcine insulin is omitted from the calculation. The side products are mostly des(Ala $)^{\mathrm{B} 30}$ insulin and various reaction products of this insulin derivative.

Using a shorter reaction time and a lower enzyme concentration, under otherwise identical conditions, resulted in a higher proportion of Peak I relative to the amount of porcine insulin converted in the reaction (Figure $4 \mathrm{~B}$ and Table II B). This was to be expected, but surprisingly the amino acid composition indicated that Peak I contained only the insulin species INS-Pro-LysThr-Thr-NH2. Thus, even under these conditions the initial coupling product, INS-Pro-Lys$\mathrm{Thr}-\mathrm{NH}_{2}$, does not accumulate, but reacts further to form INS-Pro-Lys-Thr-Thr- $\mathrm{NH}_{2}$. In this experiment, very little of the incorporated threonine was present in insulin derivatives eluting in Peak II (which was mostly composed of unconverted porcine insulin and the hydrolysis product, INS-Pro-Lys-OH), i.e. very little human insulin was formed. The yield of the conversion of porcine insulin to INS-Pro-LysThr-Thr- $\mathrm{NH}_{2}$ is $30 \%$ when unconverted porcine insulin is excluded from the calculation.

In conclusion, at $\mathrm{pH} 9.5$ the accumulation of the initial transpeptidation product, INS-ProLys-Thr- $\mathrm{NH}_{2}$, was not observed due to the relatively low peptidase activity compared to the amidase activity of CPD-Y under these condi-

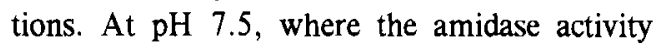
generally is lower than the peptidase activity (1), it was expected that the peptide amide formed in the reaction would be more stable than at $\mathrm{pH}$ 9.5. The results shown in Figure 5 confirmed this since Peak I comprised $20 \%$ of the total insulin pool as opposed to $3 \%$ when the reaction was performed at $\mathrm{pH} 9.5$ (Figure $4 \mathrm{~A}$ ). In both reactions approximately $75 \%$ of the porcine insulin had been converted. However, since the threonine content of Peak I (3.65) (Table III) was larger than 2.87 (the threonine analysis of authentic human insulin) it is evident that the initial transpeptidation product was apparently 


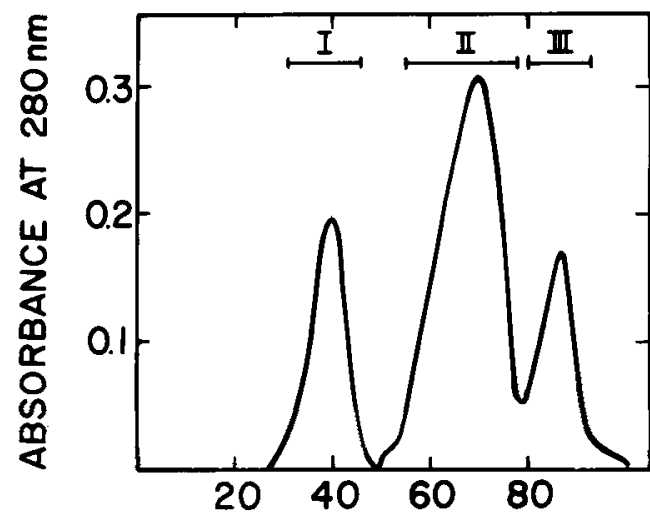

FRACTIONS

Figure 5. DEAE chromatography of the combined insulin derivatives formed in the CPD-Y catalyzed reaction between porcine insulin and $\mathrm{H}-\mathrm{Thr}-\mathrm{NH}_{2}$.

The reaction conditions were: 2 mm-porcine insulin, $0.5 \mathrm{~m} \mathrm{H}-\mathrm{Thr}-\mathrm{NH}_{2}, 1.5 \mathrm{~m}$-guanidine hydrochloride, $15 \mu \mathrm{m}-\mathrm{CPD}-\mathrm{Y}, \mathrm{pH} 7.5$, reaction time 2 hours. The amino acid composition of the insulin pool after Sephadex G-50 chromatography (Table III) indicated that $78 \%$ of the porcine insulin had been consumed in the reaction. $75 \mathrm{mg}$ reacted insulin was applied to the DEAE column $(2.5 \times 25 \mathrm{~cm})$. Volume of collected fractions: $8 \mathrm{ml}$.
Table III

Amino acid compositions of the peaks in Figure 5.

\begin{tabular}{lcccc}
\hline & Pool & Peak I & Peak II & Peak III \\
\hline Thr & 2.55 & 3.65 & 2.52 & 2.50 \\
Ala & 1.22 & 1.09 & 1.52 & 1.02 \\
Lys & 0.55 & 0.99 & 0.74 & 0.06 \\
Area (\%) & & 21 & 61 & 18 \\
\hline
\end{tabular}

Insulin components:

Peak I $\quad 80 \%$ INS-Pro-Lys-Thr-Thr-NH 2 $20 \%$ INS-Pro-Lys-Thr- $\mathrm{NH}_{2}$

Peak II: $\quad 52 \%$ INS-Pro-Lys-Ala-OH $22 \%$ INS-Pro-Lys-Thr-OH $26 \%$ INS-Pro-Thr- $\mathrm{NH}_{2}$

Peak III: Degradation products

The amino acid composition of the pool refers to the analysis of the insulin fraction after its separation from enzyme and low molecular weight materials by gel chromatography on Sephadex G-50. Peak compositions are based on the amino acid composition and the results of the digestion experiments with CPD-Y and CPD-A (see section 2).

only $4 \%$. The reactions were performed at $\mathrm{pH}$ 10.0 where CPD-Y is completely devoid of peptidase activity, thus rendering the products of

Table IV

CPD-Y catalyzed deamidations of Peak I from Figures $4 B$ and 5 .

\begin{tabular}{lccccccc}
\hline & \multicolumn{2}{c}{$\begin{array}{c}\text { Peak I } \\
\text { Before deamidation }\end{array}$} & \multicolumn{3}{c}{$\begin{array}{c}\text { Peak II } \\
\text { After deamidation }\end{array}$} \\
\cline { 2 - 7 } Figure & Thr & Ala & Lys & Thr & Ala & Lys \\
\hline 4 B & 4.01 & 1.03 & 1.00 & 2.81 & 1.00 & 1.00 \\
5 & 3.65 & 1.08 & 1.00 & 2.79 & 1.09 & 1.01 \\
\hline
\end{tabular}

The analytical data from digestions with CPD-A, CPD.Y and trypsin combined with the above amino acid compositions suggest that the deamidated fractions are composed of the following insulin derivatives:

Figure 4 B: $96 \%$ INS-Pro-Lys-Thr-OH, 2\% INSPro-Lys-OH, $2 \%$ INS-Pro-Lys-Thr-Thr-OH.

Figure 5: $97 \%$ INS-Pro-Lys-Thr-OH, 3\% INS-ProLys-OH. 


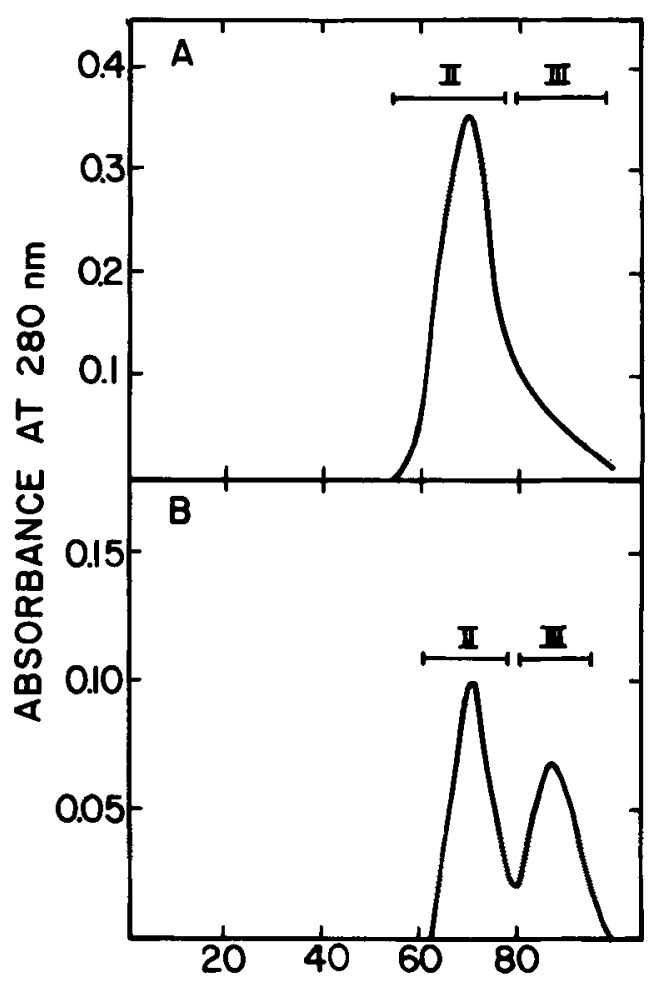

FRACTIONS

Figure 6. DEAE chromatography of the insulin derivatives formed in the CPD-Y catalyzed reaction between des(Ala)B30insulin and $\mathrm{H}-\mathrm{Thr}-\mathrm{NH}_{2}$. The reaction conditions were: $4 \mathrm{~mm}$-des(Ala)B 30 insulin, $0.5 \mathrm{~m} \mathrm{H}-\mathrm{Thr}-\mathrm{NH}_{2}, 5 \mu \mathrm{M}$-CPD-Y, $\mathrm{pH} 7.5$, reaction time 60 minutes. The amino acid composition of the insulin pool (Table V A) indicated that $72 \%$ of the $\operatorname{des}(\mathrm{Ala}) \mathrm{B} 30_{\text {insulin }}$ had been consumed in the reaction. $20 \mathrm{mg}$ reacted insulin was applied to the DEAE column $(1.5 \times 26 \mathrm{~cm})$. Volume of collected fractions: $3 \mathrm{ml}$.

B. DEAE chromatography of the insulin derivatives formed in the CPD-Y catalyzed deamidation of Peak II from $A$. The reaction conditions were: 2 mM-winsulin«, $10 \mu \mathrm{M}$-CPD-Y, $\mathrm{pH} 10.0$, reaction time 15 minutes. $8 \mathrm{mg}$ reacted insulin was applied to the DEAE column $(1.5 \times 26 \mathrm{~cm})$. Volume of collected fractions: $3 \mathrm{ml}$.
Table V A

Amino acid compositions of the peaks in Figure $6 \mathrm{~A}$.

\begin{tabular}{lcccc}
\hline & Pool & Peak I & Peak II & Peak III \\
\hline Thr & 2.55 & & 2.57 & 2.22 \\
Ala & 1.04 & none & 1.04 & 1.04 \\
Lys & 0.28 & & 0.36 & 0.08 \\
Area (\%) & & & 85 & 15 \\
\hline
\end{tabular}

Insulin components:

Peak II: $36 \%$ INS-Pro-Lys-OH

$64 \%$ INS-Pro-Thr-NH 2

Peak III: $65 \%$ INS-Pro-OH

$27 \%$ INS-Pro-Thr-OH

$8 \%$ INS-Pro-Lys-OH

Table V B

Amino acid compositions of the peaks in Figure 6 B.

\begin{tabular}{lcccc}
\hline & Pool & Peak I & Peak II & Peak III \\
\hline Thr & 2.57 & & 2.36 & 2.93 \\
Ala & 0.98 & none & 1.04 & 0.99 \\
Lys & 0.30 & & 0.57 & 0.07 \\
Area (\%) & & & 55 & 45 \\
\hline
\end{tabular}

Insulin components:

Peak II: $60 \%$ INS-Pro-Lys-OH

$40 \%$ INS-Pro-Thr-NH 2

Peak III: $98 \%$ INS-Pro-Thr-OH

$2 \%$ INS-Pro-Lys-OH

The amino acid composition of the pool refers to the analysis of the insulin fraction after its separation from enzyme and low molecular weight materials by gel chromatography on Sephadex G50. The peak composition is based on the amino acid composition of individual peaks and the results of the digestion experiments with CPD-Y and CPD-A (see section 2). the reactions stable. After separation of the reacted insulin from enzyme and low molecular weight material by chromatography on Sephadex G-50, the material was chromatographed on DEAE Sephadex A-25 using procedures identical to those in Figures 4 and 5 . The products of the reactions eluted in Peak II as expected, while the unreacted material $(<10 \%)$ eluted in Peak I. No Peak III was present in either of the two cases, i.e. no insulin derivatives without lysine were formed. As indicated from the results in Table IV, only the threonine content was affected by these reactions. This is in agreement with the expected absence of peptidase activity of 
CPD-Y at this pH. The amino acid compositions of Peak II from both reactions (Table IV) are almost identical to the analysis of human insulin: $\mathrm{Thr}=2.87$, Ala $=1.05$, Lys $=0.98$. The digestion of the deamidated products with CPD-Y, CPD-A and trypsin indicated that both samples contain approximately $95 \%$ pure human insulin (for details see Table IV). This suggests that the insulin derivative INS-Pro-Lys-Thr-Thr- $\mathrm{NH}_{2}$ reacts almost exclusively via the peptidyl amino acid amide hydrolase activity while INS-ProLys-Thr- $\mathrm{NH}_{2}$ reacts mostly via the amidase activity. The overall yield for the conversion of porcine insulin to human insulin are in both cases approximately $30 \%$ based on the amount of converted insulin.

\subsection{Conversion of des(Ala) ${ }^{\mathrm{B} 30}$ insulin to

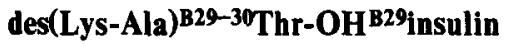

While the transpeptidation reactions performed on porcine insulin required relatively high concentrations of CPD-Y, similar reactions could be performed on des(Ala $)^{\mathrm{B} 30}$ insulin with much less enzyme, indicating that this insulin derivative is a better substrate of CPD-Y than porcine insulin. Unfortunately, the incorporation of amino acid amides with uncharged side groups in place of the C-terminal lysine of $\operatorname{des}(\mathrm{Ala})^{\mathrm{B} 30}$ insulin results in a product which has the same charge as the substrate. This complicates the isolation of the transpeptidation product. However, since the product, after deamidation, can be separated from the starting material, the following approach was adopted: After reaction of $\operatorname{des}(\mathrm{Aia})^{\mathrm{B} 30}$ insulin with $\mathrm{H}-\mathrm{Thr}-\mathrm{NH}_{2}$, the coupling product INS-Pro-Thr-NH $\mathrm{N}_{2}$, together with the substrate, INS-Pro-Lys-OH, were separated from the hydrolysis product, INS-Pro-OH (Figure $6 \mathrm{~A}$ ). From the peak areas and the composition of the individual peaks (Table V A), it was evident that the reaction mixture consisted of $28 \%$ INS-Pro-Lys-OH, $54 \%$ INS-Pro-Thr- $\mathrm{NH}_{2}$ and $18 \%$ INS-Pro-OH. A deamidation reaction was then performed on the peak containing INSPro-Thr- $\mathrm{NH}_{2}$ and unconverted INS-Pro-Lys$\mathrm{OH}$. The product, INS-Pro-Thr-OH, was isolated by ion exchange chromatography (Figure $6 \mathrm{~B}$ and Table V B). Under the conditions employed, the reaction was not complete since residual INS-Pro-Thr- $\mathrm{NH}_{2}$ was present together with unconverted INS-Pro-Lys-OH in Peak II. Apparently deamidation of INS-Pro-Thr- $\mathrm{NH}_{2}$ proceeded via CPD-Y's amidase activity and not the peptidyl amino acid amide hydrolase activity, since no detectable INS-Pro-OH was formed in the deamidation reaction. Thus, the yield of deamidation with this particular peptide is quantitative.

\section{DISCUSSION}

The ability of CPD-Y to catalyze the formation of peptide bonds is well documented, and the potential of using this enzyme in step-wise peptide synthesis has been discussed $(2,20,21$, $22,23)$. The transpeptidation reactions which can be catalyzed by CPD-Y as well might result in its use in protein semisynthesis, particularly for the direct exchange of the C-terminal amino acid in a peptide or protein by amino acid derivatives or other nucleophiles $(1,3)$. Such reactions, specific for the C-terminal of the peptide chain, have hitherto only been possible in special cases.

Porcine insulin is one example of a protein where the exchange of a C-terminal amino acid residue would be of significant interest. If the alanyl residue occupying the $\mathrm{C}$-terminal position of the B-chain is exchanged with a threonyl residue, human insulin is obtained. This semisynthetic problem was first solved by RUTTENBURG in 1972 (15) with a procedure involving tryptic cleavage of porcine insulin to form des

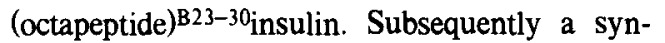
thetic octapeptide corresponding to the $\mathrm{C}$ terminal of human insulin, was coupled to form human insulin. This first procedure has since been improved $(9,14)$, but an efficient procedure for the production of human insulin by semisynthesis has only recently emerged. This procedure is based on the specific removal of the C-terminal alanyl residue in porcine insulin by CPD-A (18), followed by a trypsin catalyzed condensation of a threonine derivative to the resulting des(Ala) ${ }^{\mathrm{B} 30}$ insulin (12). Some improvements of this procedure have been reported $(6$, 13).

Several procedures for the CPD-Y catalyzed exchange of $\mathrm{C}$-terminal amino acid residues have previously been tested using small synthetic peptides as substrates (3). A replacement of the 
ultimate amino acid residue by direct transpeptidation using another amino acid or amino acid derivative as nucleophile is the most direct approach possible, and its feasibility was thus tested for the conversion of porcine insulin to human insulin.

Since no preparative techniques to our knowledge are capable of separating human insulin from porcine insulin and $\operatorname{des}(\mathrm{Ala}){ }^{\mathrm{B} 30}$ insulin, it would be advantageous if the coupling product had a different charge than the starting material and the hydrolysis product, thereby rendering it easy to isolate by ion exchange chromatography. The coupling product with $\mathrm{H}-\mathrm{Thr}-\mathrm{OMe}$ or $\mathrm{H}$ Thr- $\mathrm{NH}_{2}$ as nucleophiles would fulfill this criteria. From the results obtained with these two nucleophiles (Figures $2 \& 3$ ) it is apparent that although $\mathrm{H}-\mathrm{Thr}-\mathrm{OMe}$ can be incorporated in place of the C-terminal alanyl residue in the Bchain of porcine insulin, no INS-Pro-Lys-Thr$\mathrm{OMe}$ is present in the reaction mixture. With $\mathrm{H}$ Thr- $\mathrm{NH}_{2}$ as nucleophile, some INS-Pro-LysThr- $-\mathrm{NH}_{2}$ was detected and could be isolated. However, the majority of the incorporated threonine was present as human insulin, which eluted in Peak II together with unconverted porcine insulin and des $(\mathrm{Ala})^{\mathrm{B} 30}$ insulin which is the hydrolysis product of the reaction. This indicated that under the conditions of coupling (pH 9.5) the initial coupling product, INS-ProLys-Thr $-\mathrm{NH}_{2}$, was a better substrate of CPD-Y than porcine insulin, INS-Pro-Lys-Ala-OH. This procedure was therefore not suitable for the synthesis of pure human insulin.

Since the peptidase activity of CPD-Y at neutral $\mathrm{pH}$ generally is much higher than its amidase activity (1), and since CPD-Y catalyzed transpeptidations using amino acid amides as nucleophiles are possible at neutral $\mathrm{pH}$ (3), it was expected that the coupling product, INS-ProLys-Thr- $\mathrm{NH}_{2}$, would be more stable at $\mathrm{pH} 7.5$ than at $\mathrm{pH}$ 9.5. Surprisingly, the amidase activity at pH 7.5 was sufficiently high to cause formation of the oligomer, INS-Pro-Lys-ThrThr- $\mathrm{NH}_{2}$ (Table III). It is thus evident that, contrary to previous observations, an amide (INS-Pro-Lys-Thr- $\mathrm{NH}_{2}$ ) may be as good a substrate of CPD-Y as a free peptide (INS-ProLys-Ala-OH) at neutral $\mathrm{pH}$. The explanation of this is most likely found in the sequence of the Bchain of porcine insulin. For a direct replacement of alanine, the penultimate lysine residue in INSPro-Lys-Ala-OH must bind in the $S_{1}$ site of the enzyme (BERGER-SCHECHTER nomenclature (16)). The present data indicate that this residue which is positively charged at neutral $\mathrm{pH}$ binds less well at the $S_{1}$ site than the threonyl residue, since deamidation of INS-Pro-Lys-Thr $-\mathrm{NH}_{2}$ takes place with the threonyl residue bound at the $S_{1}$ site.

At first glance it thus appeared that our attempts to synthesize pure human insulin via INS-Pro-Lys-Thr- $\mathrm{NH}_{2}$ would be unsuccessful due to the formation of INS-Pro-Lys-Thr-Thr$\mathrm{NH}_{2}$. However, when the insulin derivatives, present in Peak I of Figures $4 \mathrm{~B}$ and 5, were deamidated with CPD-Y at $\mathrm{pH} 10$ where the enzyme has no peptidase activity, almost pure human insulin resulted. The explanation of this result lies in the capacity of CPD-Y to cleave off an amino acid amide residue, i.e., the enzyme exhibits peptidyl amino acid amide hydrolase activity under conditions where the enzyme also exhibits amidase activity (1). Some peptide amides react predominantly via the amidase activity while others react via the peptidyl amino acid amide hydrolase activity, apparently dependent on the C-terminal amino acid residue (1). As indicated by the present results with insulin summarized in Table IV - the penultimate residue can also be critical for the ratio of amidase over peptidyl amino acid amide hydrolase activity, since the insulin derivative INSPro-Lys-Thr-Thr- $\mathrm{NH}_{2}$ reacts almost exclusively via the peptidyl amino acid amide hydrolase activity to form approximately 95\% INS-ProLys-Thr-OH while INS-Pro-Lys-Thr- $\mathrm{NH}_{2}$ reacts predominantly via the amidase activity to form INS-Pro-Lys-Thr-OH. While this fortuitous situation makes it possible to use CPD-Y to convert porcine insulin to human insulin, it is evident that the approach employed suffers from the fact that the starting material (porcine insulin) is a poor substrate for CPD-Y relative to the initial transpeptidation product, INS-ProLys-Thr- $\mathrm{NH}_{2}$. Although the formation of the oligomer, INS-Pro-Lys-Thr-Thr-NH 2 , turned out not to be a problem for the CPD-Y catalyzed synthesis of human insulin, substantial amounts of human insulin which could not be isolated was formed due to in situ deamidation of insulin amide formed in the reaction. Since human 
insulin could only be isolated via the insulin amide derivative, the effective yield was much lower than the actual coupling yield, and as a consequence the overall yield of the conversion of porcine insulin to human insulin was only $30 \%$, based on the amount of converted porcine insulin.

The yield of the above procedure for the semisynthesis of human insulin is not as high as reported by MORIHARA et al. $(12,13)$ and subsequently by GaTTNER et al. (6). However, the present procedure is all enzymatic, while the procedure of MORIHARA et al. involves a chemical step in the removal of the C-terminal blocking group with possible side reactions as a consequence.

The transpeptidation reaction on des (Ala) ${ }^{\mathrm{B} 30_{\text {insulin }}}$ is presented to demonstrate a case where the coupling product, INS-Pro-Thr- $-\mathrm{NH}_{2}$ is stable under the conditions of coupling and where deamidation can be performed without interference by peptidyl amino acid amide hydrolase activity. In other words, the sequence INS-Pro-Lys-OH forms an ideal case for the direct CPD-Y catalyzed exchange of a C-terminal amino acid residue in a protein. Here, the overall yield of the conversion is much higher than for the semisynthesis of human insulin.

\section{ACKNOWLEDGEMENTS}

The authors are indepted to professor MARTIN OTTESEN for many helpful suggestion at all stages of the work. The excellent technical assistance of Mss. Bodil Corneliussen, Irene Simonsen, Pia Poulsen and Merete Sonne is gratefully acknowledged. PIA Poulsen is also acknowledged for performing the drawings. F. WiDMER gratefully acknowledges the Swiss National Science Foundation for a Post-Doctoral Fellowship.

\section{REFERENCES}

1. BReddam, K., F. Widmer \& J. T. Johansen: Carboxypeptidase $\mathrm{Y}$ catalyzed transpeptidations and enzymatic peptide synthesis. Carlsberg Res. Commun. 45, 237-247 (1980)

2. BREDdAM, K., F. Widmer \& J. T. Johansen: Influence of the substrate structure on carboxy peptidase $\mathrm{Y}$ catalyzed peptide bond formation. Carlsberg Res. Commun. 45, 361-367 (1980)
3. Breddam, K., F. Widmer \& J. T. Johansen: Carboxypeptidase $\mathrm{Y}$ catalyzed $\mathrm{C}$-terminal modifications of peptides. Carlsberg Res. Commun. 46, 121-128 (1981)

4. Davis, B. J.: Disc electrophoresis - II. Method and application to human serum proteins. Annals. N. Y. Acad. Sci. 121, 404-427 (1964)

5. Gattner, H.-G., E. W. Schmitt \& V. K. NaIthanI: Semisynthetic experiments in the C terminal range of insulin. Semisynthetic peptides and proteins, Acad. Press 1978. Eds.: R. E. Offord \& C. DiBello, p. 181-191

6. Gattner, H.-G., W. Danho, R. Knorr, V. NalTHANI \& H. ZAHN: Peptides 1980. Proceedings of the sixteenth European Peptide Symposium. Ed. K. Brunfeldt, Scriptor, Copenhagen 1981, p. 372-377

7. Geiger, R.: Chemie des Insulins. ChemikerZeitung 100, 111-128 (1976)

8. Hayashi, R., Y. BaI \& T. Hata: Kinetic parameters for the hydrolysis of synthetic substrates. J. Biochem. (Tokyo) 77, 69-79 (1975)

9. Inouye, K., K. Watanabe, K. Morihara, Y. Tochino, T. Kanaya, J. Emura \& S. SakakiBARA: Enzyme-assisted semisynthesis of human insulin. J. Am. Chem. Soc. 101, 751-752 (1979)

10. Johansen, J. T., K. Breddam \& M. Ottesen: Isolation of carboxypeptidase $\mathrm{Y}$ by affinity chromatography. Carlsberg Res. Commun. 41, 1-14 (1976)

11. LeE, H.-M. \& J. F. Riordan: Does carboxypeptidase $\mathrm{Y}$ have intrinsic endopeptidase activity. Biophys. Res. Commun. 85, 1135-1142 (1978)

12. Morihara, K., T. Oka \& H. Tsuzuki: Semisynthesis of human insulin by trypsin-catalyzed replacement of Ala-B 30 by $\mathrm{Thr}$ in porcine insulin. Nature 280, 412-413 (1979)

13. Morihara, K., T. OKa, H. Tsuzuki, Y. Tochino \& T. KANAYA: Achromobacter protease I catalyzed conversion of porcine insulin into human insulin. Biochem. Biophys. Res. Commun. 92, 396-402 (1980)

14. Obermeier, R.\& R. Geiger: A new semisynthesis of human insulin. Hoppe Seyler's Z. Physiol. Chem. 357, 759-767 (1976)

15. RuttenberG, M. A.: Human insulin: Facile synthesis by modification of porcine insulin. Science 177, 623-625 (1972)

16. Schechter, I. \& B. Berger: On the size of the active site of proteases. I. Papain. Biochem. Biophys. Res. Commun. 27, 157-162 (1972)

17. Schlichtrkull, J., J. Brange, Aa. ChristenSeN, O. Hallund, L. Heding \& K. JøRgensen: Chemical aspects of insulin - antigenicity. Diabetes 21, 649-656 (1972) 
18. Schmitt, E. \& H.-G. Gattner: Verbesserte Darstellung von des-alanylB30-insulin. HoppeSeyler's Z. Physiol. Chem. 359, 799-802 (1978)

19. Sluyterman, L.: Electrophoretic behaviour in filter paper and molecular weight of insulin. Biochem. Biophys. Acta 17, 169-176 (1955)

20. Widmer, F. \& J. T. JOHANSEN: Enzymatic peptide synthesis. Carboxypeptidase $Y$ catalyzed formation of peptide bonds. Carlsberg Res. Commun. 44, 37-46 (1979)

21. WidMeR, F., K. BREDdAM \& J. T. JoHANSEN: Carboxypeptidase $Y$ catalyzed peptide synthesis using amino acid alkyl esters as amine compo- nents. Carlsberg Res. Commun. 45, 453-463 (1980)

22. Widmer, F., K. Breddam \& J. T. Johansen: Influence of the structure of amine components on carboxypeptidase $\mathrm{Y}$ catalyzed amide bond formation. Carlsberg Res. Commun. 46, 97-106 (1981)

23. Widmer, F., K. Breddam \& J. T. Johansen: Carboxypeptidase $\mathrm{Y}$ as a catalyst for peptide synthesis in aqueous phase with minimal protection. In: Proc. 16th European Peptide Symposium. K. Brunfeldt ed., Scriptor. Copenhagen pp. 46-55 (1981) 